\title{
PReS-FINAL-2353: Are rasopathies new monogenic predisposing conditions to the development of systemic lupus erythematosus?
}

\author{
B Bader-Meunier $^{1 *}, \mathrm{H}_{\text {cave }^{2}}$, N jeremiah ${ }^{3}$, F Rieux-Laucat ${ }^{3}$ \\ From 20th Pediatric Rheumatology European Society (PReS) Congress \\ Ljubljana, Slovenia. 25-29 September 2013
}

\section{Introduction}

RASopathies (Noonan syndrome (NS) and Noonan-related syndromes) are neurodevelopmental syndromes resulting from germline mutations in genes that participate in the rat sarcoma/mitogen-activated protein kinases (RAS/ MAPK) pathway (PTPN11, SOS1, RAF, KRAS or NRAS and $S H O C 2$ ). Some monogenic conditions are associated with the development of systemic lupus erythematosus (SLE), and a few reports described the association of SLE, with NS.

\section{Objectives}

We aim to search for a relationship between RASopathy and the development of SLE.

\section{Methods}

We reported for the first time on a 13-year-old boy with NS with loose anagen hair (NSLAH) resulting from mutation in SHOC2 who developed an autoimmune disorder which fulfilled four American College or Rheumatology (ACR) criteria for the classification of SLE (polyarthritis, pericarditis, antinuclear antibodies, anti-DNA antibodies). The case report then prompted a literature review by a systematic search for English and French articles on the subjects of RASopathies and SLE that had English abstracts in PubMed from 1966 to 2012.

\section{Results}

We identified seven additional patients with RASopathy and SLE. The male-to-female ratio was 1:1, and age at onset of SLE ranged from 5 to 32 years. The most common features were polyarthritis (7/8 patients), auto- immune cytopenia (4/8 patients) and pericarditis ( $4 / 8$ patients) while only one patient presented with skin involvement.

\section{Conclusion}

The association of two rare diseases in eight patients suggests that RASopathies may be associated with the development of SLE, which is characterized by a higher male-to-female ratio, a lower rate of skin involvement and a higher rate of pericarditis than "classic" SLE.

\section{Disclosure of interest}

None declared.

\section{Authors' details}

'Hôpital Necker, France. ${ }^{2}$ hôpital R.Debré, France. ${ }^{3}$ INSERM U768, Paris, France.

Published: 5 December 2013

doi:10.1186/1546-0096-11-S2-P343

Cite this article as: Bader-Meunier et al:: PReS-FINAL-2353: Are rasopathies new monogenic predisposing conditions to the development of systemic lupus erythematosus? Pediatric Rheumatology 2013 11(Suppl 2):P343.

${ }^{1}$ Hôpital Necker, France

Full list of author information is available at the end of the article 